\title{
A Clinical Study of Pelvic Inflammatory Disease and Its Management with Unani Drugs
}

\begin{abstract}
Authors
Dr Amtul Aziz Tahseen ${ }^{1}$, Dr Amena Begum ${ }^{2}$, Dr Wasia Naveed ${ }^{3}$

${ }^{1}$ M.D. [Unani In Qabalat -Wo- Amraz-E-Niswan] Government Nizamia Tibbi College, Hyderabad. Email: amtul.success@gmail.com

${ }^{2}$ Assistant Professor, Qabalat -Wo- Amraz-E-Niswan Government Nizamia Tibbi College, Hyderabad Email: dramina.sd@gmail.com

${ }^{3}$ Principal, Professor and HOD in Qabalat -Wo- Amraz-E-Niswan Govt Nizamia Tibbi College Hyderabad Email: wasia_naveed@gmail.com

ABSTRACT

Pelvic Inflammatory Disease is an important public health problem with serious repercussion on women's health and wellbeing. According to World health organization (WHO), 330 million cases are reported to have RTI while 5\% of all the infections are contributing to RTI in rural India and $40 \%$ new infections are reported annually. There are very few studies on pelvic inflammatory disease and its management with unani drugs. The purpose of the study was to clinically study about pelvic inflammatory disease as a syndrome associated with ascending, descending infections and thereby managing the disease while comparing the two different groups of unani medicines in order to maintain the viable reproduction capabilities. In the present research study, sixty cases were selected from OPD of Government Nizamia General Hospital, Hyderabad. They were randomly divided into two groups of 30 each according to the treatment planned. PID has been treated with two comparative groups Group-A and Group- $B$ and the results are successively encouraging with Group-B medicine. The Mean $\pm S D$ of Group-A Patient is $83.4 \pm 16.79$ The Mean $\pm S D$ Value of group- $B$ is $86.77 \pm 15.31$ The T-value is 0.80 in Group-A and Group-B. This shows that there is no significant difference between the responses of two groups. Both groups have shown good response but group $B$ response was better than group A.

KEYWORDS: Pelvic Inflammatory Disease(PID), WarmeAzaa-e-Ana,Warme Reham, Warme Qazifainwa Qusyatur-Reham, Microbes, Ajsame-Qabisa.
\end{abstract}

\section{INTRODUCTION}

The Pelvic Inflammatory Disease is defined as the inflammation of upper reproductive tract involving fallopian tubes and ovaries. According to ancient unani physicians, Warmeaaza-e-ana (PID) is defined aswarmeqazifain-va mubaiyazain and it includes warme- reham, warmequsyaturreham, warmeqazifaino- mubaiyazain. The infection so called tadiyaa is caused by ajsaam-e-khabeesa or garibawhich arises after natural calamities accounting for warme-azaa-e-ana ${ }^{1}$. PID is a polymicrobial infection $^{2}$ 
Intracellular organisms ( microbes ) controls the expression of virulent factor molecules and produces mutant phenotypes changing the genetic sequence as per variants Chronicity of infections by microbes causing PID have sparked the possible initiators to various cancers ${ }^{3}$. Mycoplasma genitalium an STI agent causes PID ${ }^{4}$ Dr A. Kriplani et al, ${ }^{5}$ Shirish et $\mathrm{al}^{6}$ reported genital TB infection causing tubal blockage. Belfort et al. $^{7}$ reported about the tubal block affecting sterility. Siddharta et $\mathrm{al}^{8}$ reported minor tubal defects as the unnoticed causes for unexplained infertility

PID and its confirmation by laproscopic visualization, histological, microbiological, clinical evidence of salpingitis was revealed by Frank et al ${ }^{9}$

Kalpana et $\mathrm{al}^{10}$ reported abortion sticks causing hydrosalpinx. Mahendra et al ${ }^{11}$ presented cases on left twisted hydrosalpinx as an acute abdomen

Prevalance of PID: Acute PID occurs in 1-2\% of young, sexually active women each year. $85 \%$ of infection is acquired by sexually active women of reproductive age. $15 \%$ of infections occur after procedures that break cervical mucous barrier. $33 \%$ occurs in nulliparous women. Re-infection by untreated male partner occurs in $80 \%$ patients. According to World health organization $\left(\mathrm{WHO}^{12}\right)$, 330 million cases were reported to have RTI while $40 \%$ new infections were reported annually.

Therefore this study was designed for early identification and management of pelvic inflammatory disease with unani medicines, thereby enhancing women's reproductive health.The purpose of this study is toclinically study about pelvic inflammatory disease and compare the efficacy of the two groups unani medicine.

\section{METHODOLOGY}

Patients were selected from the Gynaec. OPD and treated as inpatient in gynaecological ward (ward no 4) of Govt. Nizamia General Hospital, Charminar, Hyderabad.

Randomised Single research blind trial with pre and post-test evaluation, 60 married and unmarried women, 30 patients in each group, were selected. All selected patients were administered the trial drug formula. The study was conducted for a period of 10 days of each cycle upto 3 cycles (3 months).

Study Plan: Two groups are planned with identical features, Group A and Group B and they are classified according to the treatment given.

Females aged 20-50 years, married/unmarried constituting all socioeconomic groups with Pelvic Inflammatory Disease/free fluid in Pouch of Douglas were included in the study

All malignancies, genital TB, congenital malformations of female genital tract, acute abdomen with acute appendicitis, ectopic pregnancy, acute PID with surgical emergencies, blood dyscrasias and also patients suffering from septic shock after abortion and delivery were excluded from the study. Lower abdominal pain, low backache, pain during menstruation, micturition, coitus, fever with chills, nausea, vomitings; Per-abdomen examination such as Distention/tenderness/rigidity in the lower abdomen as subjective and objective diagnostic criteria were carried out respectively. Pervaginal examination such as tenderness/ mass in the fornices; perspeculum examination such as purulent discharges from the cervix were clinically assessed. Further laboratory investigations were carried out which included CBP and ESR; CUE; RBS; serology] Cervical Pap smear, Vaginal swab culture and sensitivity and Ultrasonography. Routine and special investigations were done before and after three cycles. 
ADMINISTRATION OF DRUGS USED IN THE TRIAL:

1. Oral decoction and powdered drugs

2. Zimad for local application per abdomen in suprapubic region

3. Douches /syringing and Humool insertion into vagina in group-A and group-B patients respectively.

\section{Joshanda (Decoction)}

Seeds of khatmi (5g), Qubasi (5g), kasni(5g) and leaves like aftimun(3g); flowers like guletisu(5g), gulenilofer $(5 \mathrm{~g})$,gulesurq $(5 \mathrm{~g})$ and roots of mulethi (3g) are soaked in $500 \mathrm{ml}$ water kept overnight boiled in the morning, shabeyamani powder 0.25 grams added in the solution, sieved and given in two divided doses twice daily before meals Joshanda is common to both groups.

\section{Sufuf (Powder)}

Seeds of tuqmekhatmi (3g), tuqmekhaksi (3g), charaita (3g) magzegajga (3g), kalonji (3g) are taken in equal quantities, finely powered and given 5 grams twice a day before meals to groupA patients.

Leaves of Shahitra (6g), badranjboya $(4 \mathrm{~g})$, maoekhushk (4g) aftimunvilayti (4) ,finely powered grinded, sieved and given 5 grams each before meals for group-B patients.

\section{Douches (Dush)}

Leaves of kasni $(10 \mathrm{~g})$, kamni $(10 \mathrm{~g})$, neem $(10 \mathrm{~g})$, katan (10g), kamela (3g), kishniz (10g) were collected Soaked in $100 \mathrm{ml}$ of water Left overnight Boiled to half quantity sieved and administered in the form of douches for ten days and repeated at three menstrual cycles for Group-A patients.

\section{Zimad}

The extract from ghigawar leaves $(5 \mathrm{~g})$; powders of magzegajga $(3 \mathrm{~g})$, dare hald $(2 \mathrm{~g})$ and the extract of qatmi seeds $(5 \mathrm{~g})$ in group-A medicines are applied on the lower abdomen for six hours daily for a duration of 10 days for three successive cycles.
The extract from ghigawar leaves(7g), powders from jadwar fruits $((1 \mathrm{~g})$ and oils from neem $(10 \mathrm{~g})$ and kunjad $(10 \mathrm{~g})$ leaves in group-B medicines are applied on the lower abdomen for six hours daily for a duration of 10 days for three successive cycles.

\section{Pessary (Humool):}

A sterilizedsmall cotton ball is soaked in a mixture of humool.It contains leaves of charaita $(5 \mathrm{~g})$; flowers of guletisu (7g) are added in luabeisabghol $(10 \mathrm{~g})$ and roghane neem $(10 \mathrm{~g})$.It is inserted in the posterior fornix to group B patients only.

The research drugs were selected after detailed pharmacological study of unani medicines to explore the validity and efficacy in 'iltehabehouzeaana' (Pelvic Inflammatory Disease). After a concentrate study of the disease and its management described by Great Ancient Physicians, and the methodology of the unani treatment, i.e. ilaj-biz-zid. The principle actions of these drugs are muhallil-e-auramadviya (resolvent), musakkin-e-dard (analgesic), musafiyat (blood purifiers) muqawie- aamadviya (general tonic).Two trial drug formulae have been selected. All the patients of both groups were advised to take simple and nutritious diet, and to avoid spicy food.

The data was documented to compare the efficacy of two different groups of unani medicines to treat the disease.

\section{RESULTS AND DISCUSSION}

The clinical findings were assessed before and after treatment and overall scoring was done based upon the clinical, routine and special investigations. The results were drawn statistically to prove the efficacy of Unani medicines.

After a detailed research study on PID, the study indicated that maximum incidence was found in the age group 21-25 years. This disease is common in parous women in their reproductive age group.Maximum number of patients of this 
disease belonged to lower class and patients with poor nutrition were the sufferers of this disease.

It has been observed that the disease is mostly found in patients having balghami temperament. As evident from the data detailed gynaecological examination of patient is required, especially per speculum examination, is important from diagnostic point of view. Pap smear is needed for screening and swab culture is needed to confirm type of infection and causative organism.

The treatment was given as inpatient department for ten days at monthly intervals for three cycles. The diagnosed patients were divided into two groups such as group A and group B and treated with group A and group B medicines respectively; the selection of medicine was based on the properties and temperament of drugs. Both the groups contain a common oral decoction (joshanda), the other drugs vary that include an oral powder, a local applicant, douches .The group-A differs from group-B in the application of vaginal pessary

The result of the study was encouraging in this study, the historical aspects of unani medicine including the humoral theory and thoughts of various Arabic scholars have been reviewed. The effect of unani medicines between group A and group B was compared, results were drawn statistically demonstrated in the form of tables. The drugs used for the trial in this study have the properties of anti-inflammatory, analgesic, astringents, demulcent, healing, soothing.
In the present study there was an overall improvement in the remission of PID symptoms, enhancement in the lab scores, sonographic, pap smears and swab cultures to positive values. No side effects were noted with these herbal medicines.

During the treatment of PID the response with the two different drugs were studied and compared. The overall response in PID patients treated with Group A medicine of 30 patients: 14 patients i.e., $46.6 \%$ were cured, $46.6 \%$ relieved and 2 patients had poor response i.e., $6.6 \%$; whereas in group-B patients 16 patients i.e53.3\% were cured and 14 patients i.e.,46.6\%. Were relieved. It was observed that Group B medicines were effective when compared with group A.

Between these two groups of medicines group B was relatively more consistent with $53.3 \%$ (mean \pm SD response $86.77 \pm 15.31$ ) as compared to $46.6 \%$ (mean \pm SD response of $83.4 \pm 16.79$ ) in group A medicine (Table 2). At 29 degrees of freedom the $\mathrm{t}$-value is found to be 0.80 in group-A and groupB patients during the same period.

From the above statistical data, it can be concluded that null hypothesis is accepted and alternate hypothesis is rejected. This association suggests that there is no significant difference between the two groups of medicines i.e., group-A and Group-B, that means both the groups of medicines /treatment are equally good and satisfactory.

Table1: showing remission of signs in Group-A, B patients before and after treatment

\begin{tabular}{|l|l|l|l|l|l|l|l|l|}
\hline Signs & $\begin{array}{l}\text { No.of } \\
\text { patients } \\
\text { before } \\
\text { treatment } \\
\text { Group-A }\end{array}$ & $\begin{array}{l}\text { No. of } \\
\text { patients } \\
\text { before } \\
\text { treatment } \\
\text { Group-B }\end{array}$ & $\begin{array}{l}\text { No. of } \\
\text { patients } \\
\text { after } \\
\text { treatment } \\
\text { Group-A }\end{array}$ & $\begin{array}{l}\text { No. of } \\
\text { patients } \\
\text { after } \\
\text { treatment } \\
\text { Group-B }\end{array}$ & $\begin{array}{l}\text { Remission } \\
(\%)\end{array}$ & $\begin{array}{l}\text { Remission } \\
(\%)\end{array}$ & $\begin{array}{l}\chi^{2} \text { test } \\
\text { p }<0.05 \\
\text { Group- } \\
\text { Group-A }\end{array}$ & $\begin{array}{l}\chi^{2} \text { test } \\
\text { p }<0.05 \\
\text { Group- } \\
B\end{array}$ \\
\hline pra-tenderness & 22 & 15 & 6 & 2 & $16(72.7)$ & $13(86.7)$ & $\begin{array}{l}22.1 \\
\text { Sig }\end{array}$ & $\begin{array}{l}19.55 \\
\text { Sig. }\end{array}$ \\
\hline $\begin{array}{l}\text { p/v troup } \\
\text { fornices }\end{array}$ & 18 & 19 & 4 & 2 & $14(77.8)$ & $17(89.5)$ & $\begin{array}{l}19.75 \\
\text { Sig. }\end{array}$ & $\begin{array}{l}27.25 \\
\text { Sig. }\end{array}$ \\
\hline $\begin{array}{l}\text { p/sdischarges } \\
\text { from cervix }\end{array}$ & 24 & 23 & 6 & 1 & $18(75.0)$ & $22(95.6)$ & $\begin{array}{l}25.69 \\
\text { Sig. }\end{array}$ & $\begin{array}{l}38.42 \\
\text { Sig. }\end{array}$ \\
\hline
\end{tabular}


OBSERVATION: The above table shows the response of treatment in remission of symptoms showing significant response with probability of $<0.05$.

Table2:Mean \pm SD therapeutic response of patients to Group A and B patients

\begin{tabular}{|l|l|l|}
\hline GROUP & RESPONSE $($ MEAN \pm SD $)$ & t-test $(\mathrm{p}<0.05)$ \\
\hline GROUP A & $83.4 \pm 16.79$ & 0.80 \\
\hline GROUP B & $86.77 \pm 15.31$ & Not Sig. \\
\hline
\end{tabular}

According to the above table, it was observed that, among 60 patients who were treated with Group A and Group $B$ medicines, the mean \pm SD response in group-A patients is $83.4 \pm 16.79$ and that of group$\mathrm{B}$ is $86.77 \pm 15.31$.

\section{CONCLUSION}

The findings of the present study indicates that there was an overall improvement in the remission of PID symptoms, enhancement in the lab scores, sonographic, pap smears and swab cultures to positive values. No side effects were noted with these herbal medicines.

\section{REFERENCES}

1. Sheikh-ur-Rayees-Ibne-Sina Al-qanoon-fitib, 350-353

2. Dr A Multani. Text book on Obstetrics and Gynaecology: 776-794

3. Sherry et al., 2009. Integration of STD/HIV services with contraception AJOG VOL201.

4. Eva Lundin, Annikaldahl, MargarethaJurstand, Urban Kumlin, Fredrick Elgh, Nina Ohlison and Ulrika ottander, 2011. Chlamydia trachomatis and mycoplasma genetilium plasma in relation to epithelial ovarian tumors. Infectious diseases in Obstetrics and Gynaecology (http://dx.doi.org/10.1155/2011/824627)

5. AlkaKriplaniet al Textbook on Controversies in Obstetrics and Gynaecology and infertility

6. Shirish et al., 2010 IJOG JAN -FEB
7. Belfort et al. Textbook on Obstetrics and Gynaecology

8. Siddhartha ET al.2010 Minor tubal defects- The unnoticed causes of unexplained infertility Indian journal of Obstetrics and Gynaecology: 33

9. Frank et al Text book on progress in Obstetrics and Gynaecology: 323

10. KalpanaET al.2010. Abortion stick causing hysalpinx and infertility. Indian journal of Obstetrics and Gynaecology

11. Mahendra et al., 2011, Indian journal of Obstetrics and Gynaecology VOL 61, Pg81.

12. World Health Organization. Sexually transmitted infections fact sheet. 2011. [Accessed on August 25, 2011]. Available from: http://www.who.int/mediacentre/fact sheets/fs110/en/ 